\title{
EFFECTIVENESS OF NLEP ON KNOWLEDGE REGARDING PREVENTION OF OBESITY AMONG ADOLESCENTS IN SELECTED SCHOOLS
}

\author{
Ms. Maddikera Chinnadevi* | Dr. Venu Lata Saxena** \\ * Research Scholar in Himalayan University, Itanagar in Arunachal Pradesh, India. \\ ** Research Supervisor in Himalayan University, Itanagar in Arunachal Pradesh, India. \\ DOI: http://doi.org/10.47211/trr.2020.v06i01.017
}

\begin{abstract}
:
Many school-based interventions for obesity prevention have been proposed with positive changes in behaviour. The objective was to assess the effectiveness of a NLEP on prevention obesity among adolescents. Schools were randomized to intervention and control group. Methods and materials: Quantitative research approach with true experimental research design was used to find out the knowledge on prevention of obesity among school adolescents. The study was conducted among 200 adolescents studying $8^{\text {th }}, 9^{\text {th }}, 10^{\text {th }} 11^{\text {th }}$ and $12^{\text {th }}$ in selected senior secondary schools, Jalandhar, Punjab. Probability stratified sampling technique was used to select samples. Structured questionnaire was used to assess the knowledge of adolescents regarding prevention of obesity. Major findings: The overall analysis shows that poor knowledge was found in both experimental group 58\% and control group 68\% before the implementation of NLEP. In the experimental group, knowledge scores had improved after the implementation of NLEP, i.e., excellent knowledge is $36 \%$, good knowledge is $47 \%$ and average knowledge was $17 \%$. Further, in the control group, It was observed that in posttest $5 \%$ had very poor knowledge, 68\% had poor knowledge, 20\% was average knowledge and only $7 \%$ had good knowledge. From the findings it can be interpreted that NLEP improved the level of knowledge in the experimental group significantly than the control group. Pre-test knowledge of adolescents regarding prevention of obesity shows that, out of 100 experimental samples (75\%) children had inadequate knowledge, $35(23.6 \%)$ children had moderate adequate knowledge and 2(1.4\%) children had adequate knowledge. Conclusion: The results shown that, the nurse led educational package on prevention of obesity was improved the knowledge regarding prevention of obesity among the school adolescents.
\end{abstract}

Key words: Effectiveness, NLEP, Obesity, Prevention, Adolescents, Schools

\section{ABOUT AUTHORS:}

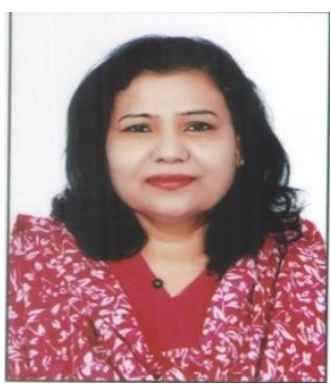

Author, Ms. Maddikera Chinnadevi is a Ph.D. Scholar at Himalayan University, Itanagar, Arunachal Pradesh, India.

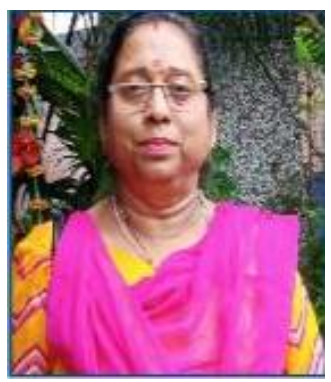

Author, Dr. Venu Lata Saxena is Ph.D. Guide at Himalayan University, Itanagar, Arunachal Pradesh, India. She is active researcher with many publications in his name. She has attended and organised various National and International conferences. 


\section{INTRODUCTION:}

Currently, the prevalence of overweight and obesity are increasing worldwide. Over 1.12 billion people worldwide are exposed to be overweight and obese up to 2030. Overweight and obesity prevalence is increasing specially in children and adolescents. Obesity ranks second after to smoking as a cause of premature death and a risk factor for development of cardiovascular diseases and metabolic disorders in adult and children. Obesity is rising within the adolescent population of India.(Bhardwaj S, Misra A, Khurana L, 2012)While the trend of obesity has stabilized in western developed nations,(Ogden CL, Carroll MD, Curtin $L R, 2010)$ it continues to rise in developing countries like India who are in final stages of nutritional stabilization. With a large part of adolescents in India, obesity with its health risks, poses a big threat to the future health of the Indian society. The third National Family Health Survey (NFHS-3, 2014) of India mentioned that, obesity increasing in north India. Obesity is the main determinant of preventable diseases. It happens from excess consumption of calories/energy compared to expenditure thus affecting health. Globally, children in particular are gaining weight, which tracks into adulthood thus increasing the danger of diseases.

\section{NEED AND SIGNIFICANCE OF THE STUDY:}

Obesity may be a chronic disease which has spread all over the world and threatens health of public globally. Its commonest cause of unhealthy diet often combined with lack of physical activity and is characterized by an excess of body fat or adiposity. It's most often defined by the body mass index (BMI) and therefore the use of body mass index for the age to define being overweight and obese in children and adolescents are well established for both clinical and public health applications. (Vaijayanthimala, M., \& Jaikumar, M. 2019)

Overweight and obesity conditions are referred to as the most common eating disorders among children and adolescents within the USA. (Mazloomy-Mahmoodabad, S. S., Navabi, Z. S., Ahmadi, A., \& Askarishahi, M. 2017). Overweight and obesity are a number of the foremost alarming challenges that humanity faces today. (Dang, D., \& Dearholt, S. L. 2017). Globally, children in particular are gaining weight, which tracks into adulthood thus increasing the danger of diseases. (Ranjani, H., Pradeepa, R., Mehreen, T. S., Anjana, R. M., Anand, K., Garg, R., \& Mohan, V. 2014). The present century had noticed that undernourished and malnourished to overweight and obesity. This transition was initially reported in developed countries but now this phenomenon has been noticed in developing countries like India, Brazil, China etc. (Popkin BM, Adair LS, $\mathrm{Ng}$ SW). In India, childhood obesity is an increasing public health problem, especially among the upper socioeconomic groups. In India, prevalence of childhood obesity and overweight within the age group of 9-15 years ranging from $9.9 \%$ to $18.5 \%$. (Srivastava, D. K., Jain, P. K., Srivastav, M., Gour, N., Choubey, B., \& Kumar, S.2015). Overweight and obesity could also be a worldwide epidemic among children of all ages. According to the World Health organization (WHO), the prevalence of overweight and obesity in children rose by $47.1 \%$ between 1980 and 2013. In 2014, Childhood obesity within the United States is a significant issue. In a nationally representative study of US children and adolescents aged 2-19 years, the prevalence of obesity was estimated at $17 \%$ in 2011-2014; extreme obesity was 5.8\% consistent with the foremost recent national Center for Health and statistics (NCHS) data (Williams, S. E., \& Greene, J. L. 2018).

A descriptive cross sectional study was conducted to assess the knowledge and attitude of adolescents towards obesity in a private school in Thrissur district Kerala, India, among students of classes 9, 10, 11 and 12 in Devamatha public school, Thrissur in 2018. The result showed that among 179 participants $46.4 \%$ of adolescents had low knowledge on obesity, 46.9 had moderate knowledge, and only $6.7 \%$ of them had adequate knowledge on obesity. (Shaji, G., Navya, C., Joseph, Aswathy, M. , \& Vidhu, J. 2018)

A study was conducted on assessment of knowledge, attitude and practice of adolescents towards obesity in the schools in Ismailia city - Egypt. Among 608 participants of whom 53.9\% were females and 50\% were in the age group of $14-15$ years. The result showed that more than half $(53.5 \%)$ of the studied participants have fair level of knowledge regarding healthy life style (diet/exercise) and causes and complications of obesity. Good level of knowledge was seen among $12.3 \%$ of the studied participants. While more than one third of them have poor knowledge (34.2\%) having a particular level of knowledge regarding healthy life style and causes and complications of obesity. ( Mosleh ,A. Ismail., Mohammed, H. K., \& Dalia, E. I. 2011)

A study was conducted on effect of teaching programme on knowledge and attitude regarding prevention of obesity. The study was conducted among 50 adolescents aged 16 to 18 years studying in I and II PUC of Pre University College, Mangalore, Karnataka. The result revealed that' $t$ ' value between pre-test and post-test attitude scores were statistically significant at 0.05 level of significance. The' $t$ ' value $(t=3.75)$ is greater than the table value ( $t(49)=2.0096$ ) and revealed that the teaching programme on prevention of obesity was effective in improving the knowledge of adolescents. (Prashanth, K., \& Umarani, J. 2013).

A study was conducted on Knowledge and attitude towards Obesity among Secondary School Students of Royal Crystal College, Ile-Ife, Nigeria. A sample of 400 student (age ranged from 10-21years) from royal crystal college (48\% males and $52 \%$ females) were involved in the study. Majority of the respondents (47\%) were 
between the ages of 13 and 15 years. The result showed that the total percentages of respondents with good level of knowledge are 58.2\% (232), and 42.2\% (168) respondents having poor knowledge level. (Omotola, A. A., \& AkeemAkinyemi, O. 2017)

Nurses are well fit to educate the adolescents on prevention of obesity in schools. It is critical in collaborating educational programs that can significantly prevent health effects of obesity. Hence the investigator carried out this present study in schools of North India.

\section{OBJECTIVES}

To determine the pre-test level of knowledge of adolescents on prevention of obesity among adolescents in selected schools.

To evaluate the effectiveness of Nurse-Led Educational Package on prevention of obesity among adolescents in terms of gain in level of knowledge score.

Find the association between demographic variables and pre-test level of knowledge of adolescents on prevention of obesity among adolescents in selected schools.

Find the relationship between Knowledge of pre and post test scores of adolescents on prevention of obesity among adolescents in selected schools.

\section{HYPOTHESES}

All Hypotheses will be tested for level of significance at 0.05 .

H1- There will be a significant difference in knowledge score of adolescents between pre and posttest regarding prevention of obesity

H2- The mean post-test knowledge score of adolescents regarding prevention of obesity in the experimental group will be significantly higher than that of the control group as measured through structured knowledge questionnaire. .

H3- There will be a significant association between pre-test level of knowledge of adolescents on their age, type of family, religion, family income, source of knowledge, any previous Knowledge.

\section{RESEARCH METHODOLOGY:}

Quantitative approach and true experimental research design of pre and post test control group was selected to carry out the present study. The sample consists of 200 school adolescents who met the inclusion criteria were selected through stratified sampling technique. After an administrative permission from selected schools two schools were randomly selected. The sampling frame was done with help of school teacher. Elements were listed and randomly assigned as experimental (100) and control group (100). Nurse led educational package (NLEP) was developed and structured closed ended knowledge questionnaire on prevention of obesity was used for the data collection. Reliability of the instrument was calculated by using karl Pearson correlation coefficient formula and significance of correlation was tested using Spearman Brown Prophesy formula. The $r^{\prime}$ value was 0.82 and the tool was found reliable. Pilot study was conducted and was found feasible and practicable. The main study was conducted in two selected schools, Jalandhar. Data was collected from 29.7.19 - 28.1.20. Pretest was conducted using closed ended questionnaire to assess the level of knowledge. The investigator personally explained the need and importance of study to the students before data collection. Soon after pre test the NLEP was implemented. Evaluation of post test was conducted after 15 days of the pre test using the same questionnaire and by the same method as pre test.

\section{Ethical Clearance:}

The ethical clearance was obtained by the Himalayan University, Itanagar, Arunachal Pradesh after proposal submission. The written administrative permission was obtained from the school principals, Jalandhar. Consent and willingness were established from all the subjects who met inclusion criteria.

\section{RESULTS:}

The highest percentage of the adolescents were in the age group of 15 and 17 years (24\%) and in control group 26 year (26\%),gender 52\% male $48 \%$ female adolescents in experimental group, $53 \%$ male and $47 \%$ females in control group, class from $8^{\text {th }}$ standard to $12^{\text {th }}$ standard from each class 20 adolescents from 13 to 17 and above age were selected, nuclear family $(83 \%)$ in experimental group $81 \%$ nuclear family, and Sikhs $55 \%$ respectively in experimental group. where as in control group majority $56 \%$ Sikhs, in experimental group $32 \%$ had monthly income of ,Rs 10,000, in control group 36\% had monthly income of ,Rs 10,000, respectively. In experimental group $85 \%$ had no previous knowledge, in control group $83 \%$ had no previous knowledge, source of no information was $85 \%$ in experimental and $83 \%$ in control group had no health information respectively. 
Table 1: Frequency and Percentage of Experimental and Control Group Level of Knowledge on Prevention of Obesity

\begin{tabular}{|c|c|c|c|c|c|c|c|c|}
\hline \multirow{2}{*}{$\begin{array}{c}\text { Level of } \\
\text { Knowledge }\end{array}$} & \multicolumn{4}{|c|}{ Experimental group } & \multicolumn{4}{c|}{ Control group } \\
\cline { 2 - 10 } & \multicolumn{2}{|c|}{ Pre test } & \multicolumn{2}{c|}{ Post Test } & \multicolumn{2}{c|}{ Pre test } & \multicolumn{2}{c|}{ Post test } \\
\cline { 2 - 10 } & $\mathbf{f}$ & $\%$ & $\mathbf{f}$ & $\%$ & $\mathbf{f}$ & $\%$ & $\mathbf{f}$ & $\%$ \\
\hline Very Poor & 32 & 32 & 0 & 0 & 8 & 8 & 5 & 5 \\
\hline Poor & 58 & 58 & 0 & 0 & 65 & 65 & 68 & 68 \\
\hline Average & 2 & 2 & 17 & 17 & 22 & 22 & 20 & 20 \\
\hline Good & 8 & 8 & 47 & 47 & 5 & 5 & 7 & 7 \\
\hline Excellent & 0 & 0 & 36 & 36 & 0 & 0 & 0 & 0 \\
\hline
\end{tabular}

Table .1 shows that poor knowledge was found in both experimental group $58 \%$ and control group $68 \%$ before the implementation of NLEP. In the experimental group, knowledge scores had improved after the implementation of NLEP, i.e., excellent knowledge is $36 \%$, good knowledge is $47 \%$ and average knowledge was $17 \%$.

Further, in the control group. It was observed that in post-test $5 \%$ had very poor knowledge, $68 \%$ had poor knowledge, $20 \%$ was average knowledge and only $7 \%$ had good knowledge. From the findings it can be interpreted that NLEP improved the level of knowledge in the experimental group significantly than the control group.

Table .2 Comparison of Paired $t$ test to assess Pre and Post-test Knowledge scores of adolescents on prevention of obesity in Control group

\begin{tabular}{|c|c|c|c|c|}
\hline \multirow{2}{*}{ Observation } & \multicolumn{2}{|c|}{ Experimental group } & \multicolumn{2}{c|}{ Control group } \\
\cline { 2 - 5 } & Mean & SD & Mean & SD \\
\hline Pre-test & 10.08 & 4.50 & 13.11 & 3.38 \\
\hline Post-test & 27.13 & 3.45 & 13.51 & 3.50 \\
\hline t-Test & \multicolumn{2}{|c|}{$\mathbf{t = 2 9 . 0 8 , p = . 0 0 0 0 1 * * *}$} & \multicolumn{2}{|c|}{$\mathbf{t = 0 . 8 8 , p = . 3 7 8 7 2}$} \\
\hline
\end{tabular}

*** Very high significant at $\mathbf{P 0 . 0 0 0 0 1}$

At pre-test statistically no significant difference was found in the level of knowledge between experimental and control group.

Chi square test was used to calculate the association. In experimental and control group the pre and post-test knowledge scores are independent of all variables that are age, gender class, type of family, religion, monthly income of family, previous knowledge and source of knowledge were non-significant $(P>0.01)$. Hence null hypotheses with regard to pre and post-test knowledge scores and demographic variables are rejected.

IMPLICATIONS:

The findings of the study have implication for nursing practice, nursing education and research.

NURSING PRACTICE

Nurse is the core member in preventive action and significant personnel in educating adolescents. The findings of the present study showed that NLEP was effective in improving the knowledge. The content of the NLEP will help the Nursing personnel in all areas like hospital, schools as well as community area and clinics for teaching the adolescents on prevention of obesity. The nurse educators in the schools can use the NLEP may be implemented to teach the adolescents and can motivate them to reduce weight and to live healthy life. It provides a frame work that it helps adolescents to understand about illness, develop positive attitude towards obese adolescents and increases knowledge in taking care of self and others too. Thus, the NLEP should be practiced as a routine care.

\section{NURSING EDUCATION}

Considering the met and unmet needs of the adolescents in the schools, as an educator the nurse has to be encouraged in the preparation of interventional module for the adolescents and their family members. This NLEP can guide the educators to prepare modules based on their objectives. Continuing education programs for nurses can improve their competence and awareness about the importance of adherence in health care. 


\section{NURSING RESEARCH}

- A longitudinal study is needed to measure the effect of NLEP overtime.

- A study can be conducted by using different instructional media for adolescents and young children who are at risk.

- The tools developed by the researcher for this study can be used with or without modifications in different settings.

- Needs of the adolescents who are at risk of obesity can be assessed and the particular aspects on LIMITATIONS nutrition and physical activity can be focused more and unhealthy foods can be retested.

- Informal teaching by the health care professionals could not be controlled.

- No control over the diet and physical activity.

\section{RECOMMENDATIONS}

- The study could replicate on a larger sample.

- Longer follow up period may be used in order to understand the long-term effects of NLEP.

- Need based study to be designed and different innovative methods can be developed for the adolescents who are unable to read and write.

- A similar study with more sessions can be conducted.

- Stigma of the Indian culture to be studied. Myths and facts, misconception to be pointed out as a separate NLEP and effectiveness of that particular aspect to be considered.

- Routine therapeutic measures to be developed for the adolescents as NLEP, as motivational DISCUSSION: therapeutic intervention of adolescents.

In the experimental group the mean knowledge score of post-test was $27.13 \pm 3.45$ significantly higher than the pre-test $10.08 \pm 4.50$, whereas, in control group, mean knowledge score of post-tests was $13.51 \pm 3.50$ was more or less similar in pre-test $13.11 \pm 3.38$. The computed experimental group paired t test value $(t=29.08 p<$ $0.0001)$ found highly significant compared to control group $(t=0.88, p<0.378)$. The findings of the present study indicate significant improvement in knowledge among the experimental group than the control group. Hence $\mathrm{HO1}$ is rejected and $\mathrm{H} 1$ is accepted. Hence it can be concluded that NELP is effective in terms of gain in knowledge score.

A study (Geetha C. 2017) denotes that, out of 148 samples111 (75\%) had inadequate knowledge, 35(23.6\%) children had moderately adequate knowledge and $2(1.4 \%)$ children had adequate knowledge. After the educational programme, the post-test knowledge of 148 samples was, $84(56.8 \%)$ children had moderately adequate knowledge and 64(43.2\%) children had adequate knowledge.-Similar findings were also reported (Lubna, M., T .2018) that, the mean level for knowledge was 4.57 (SD \pm 1.86 ) with a ranged from 0 - 10. Forty eight percent (377) of participants had poor knowledge (score 0 - 4); $46.8 \%$ (366) had moderate knowledge (score 5 - 7), and 5\% (39) had good knowledge (score 5 - 7). Recent study also reported by Mangesh, V. (2019) pre-test knowledge scores of high school adolescent, were revealed that most of them 30 (25\%) had poor knowledge, 69(57.5\%) had average knowledge and 21 (17.5\%) had good knowledge. Post-test knowledge scores of high school adolescent, revealed that most of them 118(98.33\%) had good knowledge, 2(1.66) had average knowledge. Various similar types of studies to prove the effectiveness of educational intervention in terms of gain in knowledge are also found.

\section{CONCLUSION:}

From the findings it is clear that there was improvement in knowledge through NLEP in experimental group than control group. Therefore it is concluded that NELP helps in increasing knowledge of adolescents on prevention of obesity. Based on the study findings, it is concluded that all subjects have poor knowledge. Hence, those health personnel in contact with school adolescents should screen for health effects of obesity and motivate them to include good \& nutritious food in their diet and to practice physical activity every day for one hour.

\section{CONFLICT OF INTEREST: None} ACKNOWLEDGEMENT:

The authors express sincere thanks to all the experts who validated the tool and NELP. The authors also extended gratitude to all the school adolescents who participated in study. 


\section{REFERENCES}

1. Hopkins, K. F., DeCristofaro, C., \& Elliott, L. (2011). How can primary care providers manage pediatric obesity in the real world?. Journal of the American Academy of Nurse Practitioners, 23(6), 278-288.

2. In-Iw, S., Saetae, T., \& Manaboriboon, B. (2012). The effectiveness of school-based nutritional education program among obese adolescents: a randomized controlled study. International Journal of Paediatrics, 2012.

3. Dang, D., \& Dearholt, S. L. (2017). Johns Hopkins nursing evidence-based practice: Model and guidelines. Sigma Theta Tau.

4. Gedam, D. S. (2013). Childhood obesity-challenges in the Indian scenario. Int. J. Med. Res. Rev, 1(1), 1-4.

5. Jagadesan, S., Harish, R., Miranda, P., Unnikrishnan, R., Anjana, R. M., \& Mohan, V. (2014). Prevalence of overweight and obesity among school children and adolescents in Chennai. Indian pediatrics, 51(7), 544-549.

6. Ranjani, H., Pradeepa, R., Mehreen, T. S., Anjana, R. M., Anand, K., Garg, R., \& Mohan, V. (2014) Determinants, consequences and prevention of childhood overweight and obesity: An Indian context. Indian journal of endocrinology and metabolism, 18(Suppl 1), S17.

7. Gonzaga, N. C., Araújo, T. L. D., Cavalcante, T. F., Lima, F. E. T., \& Galvão, M. T. G. (2014). Nursing: promoting the health of overweight children and adolescents in the school context. Revista da Escola de Enfermagem da USP, 48(1), 153-161.

8. Fernandes, N., Khubchandani, J., Seabert, D., \& Nimkar, S. (2015). Overweight status in Indian children: prevalence and psychosocial correlates. Indian pediatrics, 52(2), 131-134.

9. Mladenova, S., \& Andreenko, E. (2015). Prevalence of underweight, overweight, general and central obesity among 8-15-years old Bulgarian children and adolescents (Smolyan region, 20122014). Nutricion hospitalaria, 31(6), 2419-2427.

10. Mangalathil, T. X., Kumar, P., \& Choudhary, V. (2014). Knowledge and attitude regarding obesity among adolescent students of Sikar, Rajasthan. IOSR-JNHS, 3(2), 44-48.

11. Aysel Özdemir.(2015). Adolescent Obesity. International Journal of Caring Sciences, 8( 2 ), 484-86.

12. Srivastava, D. K., Jain, P. K., Srivastav, M., Gour, N., Choubey, B., \& Kumar, S. (2015). A Cross Sectional Study of the Prevalence of Obesity or Overweight and its Correlates among School Children in a Central India District.

13. Taneja, M., Maini, B., Singh, M., \& Mathur, S. K. (2015). Identification of Family Risk Factors of Obesity in Urban Adolescents of North India. Journal of Obesity and Metabolic Research, 2(2), 84.

14. Anteneh, Z. A., Gedefaw, M., Tekletsadek, K. N., Tsegaye, M., \& Alemu, D. (2015). Risk factors of overweight and obesity among high school students in Bahir Dar city, North West Ethiopia: school based cross-sectional study. Advances in preventive medicine, 2015.

15. Kamal, M. A. T. (2016). Prevalence of Overweight and Obesity among Preparatory School Adolescents in Urban Sharkia governorate, Egypt. Egyptian Pediatric Association Gazette (2016) 64, 20-25.

16. Sah, V. K., Giri, A., \& Acharya, R. (2016). Prevalence of overweight, obesity and its associated risk factors among school children aged 6-16 years of Biratnagar. Journal of Nobel Medical College, 5(2), 22-25.

17. Kaur, A. (2016). Survey of obesity among various age group girls of Punjab. Int J Phys Educ Sports Health, 3(2), 296-9.

18. Larery, T. M. (2017). Combating Childhood Obesity with Provider Education: A Quantitative Study.

19. Anand Krishna,G.,Chandrasekhar,B.(2017). Prevalence of overweight and obesity risk factors among adolescents in Tirupati schools and junior colleges. Int J of Community Med Public Health, 4(12), 4507-4512.

20. Ester Mary,P., Nalini,s., jagadesh, \& R.,vijayaraghavan.(2017). Childhood obesity and its determinants among school children. Int J Pharm Bio Sci, 8(2), 649-653.

21. Geetha,C.,Jeyalakshmi, S., \& Kamalam.,( 2017). A study to assess the effectiveness of educational program on knowledge regarding obesity among school children in selected school, puducherry. International Journal of Current Advanced Research, 6(12), 7890-92. Available Online at www.journalijcar.org

22. Shukla, N. K., Ahmad, S., Singh, J. V., Shukla, M., Soni, S., \& Shukla, R. (2018). A study on overweight and obesity among school going adolescent girls in a district of Northern India. International Journal of Medical Science and Public Health, 7(6), 474-481. 22. 22. 